\title{
CIÊNCIA E TÉCNICA NO BRASIL DURANTE A MONARQUIA (1808-89)
}

\author{
Gildo Magalhães \\ Departamento de História -FFLCH/USP
}

\section{Resumo}

Apresenta-se um panorama das principais tendências de desenvolvimentos das ciências e técnicas no Brasil sob o regime monárquico, revendo algumas das avaliações historiográficas ainda correntes. Procura-se mostrar como o liberalismo enquanto ideologia da economia política influenciou a política que acabou por predominar nesse campo.

\section{Abstract}

A panoramic view of the main trends around the scientific and technical development is presented for the period when Brazil was ruled by a monarchy, reviewing some of the historiographical evaluations still current. One seeks to show how the political economy's liberal ideology influenced the policies that ultimately predominated in this field.

\section{Pallavras-Chave}

História da Ciência • História da Técnica • Liberalismo • Estado Nacional • Brasil Monárquico

\section{Keywords}

História da Ciência • História da Técnica • Liberalismo • Estado Nacional • Brasil Monárquico 
Uivando - o Trem de Ferro - estende a cauda enorme... Enquanto nuns estranhos, íntimos vocábulos Os passageiros gazis, nos bons conciliábulos Orquestram pelo ar, em bando multiforme!... Cruz e Sousa, "Alvorada da Indústria" (1884)

\section{Introdução}

$\mathbf{E}_{\mathrm{s}}$ ste ensaio aborda temas que certamente não são novos na historiografia, permitindo-se retomar certas interpretações até clássicas e sem a pretensão de ir além de fontes secundárias, algumas conhecidas e outras nem tanto. Por abranger um período longo, procurou-se contrabalançar a desvantagem do não-aprofundamento temático com a reavaliação de alguns pontos que merecem novas discussões. Para tal, não se exime de oferecer juízos de valor sempre que isto venha privilegiar enquadramentos ainda frutíferos para as interpretações da história das ciências e técnicas no período aqui simplifica e unitariamente referido como "monárquico" (1808-1889).

A epígrafe acima, retirada da obra de um poeta ao mesmo tempo simbolista, enquanto membro de uma tendência estética, e símbolo da situação social brasileira, enquanto filho de escravos, certamente contrasta bastante com o quadro do desenvolvimento de cem anos antes. De fato, foi em 1785 que se publicou o Alvará de D. Maria I mandando fechar todas fábricas do Brasil. O edito foi revogado em 1808 por D. João VI, ao se mudar de Portugal para o Brasil, embora seu governo cuidasse em seguida de resguardar os interesses das fábricas portuguesas, para que não fossem prejudicadas pelas manufaturas brasileiras.

O desenvolvimento industrial, que nos países avançados acompanhou de perto o desenvolvimento científico, foi aqui porém arrastado e sem bons resultados, devido a uma série de motivos, entre eles a falta de recursos humanos, de capital, de redes de transporte, de mercado consumidor, bem como a mentalidade das elites, voltada para a exportação de produtos primários e importação de bens manufaturados 
(especialmente privilegiando os bens da nação hegemônica, a Grã-Bretanha, que entravam com taxas ainda menores do que dos demais países).

A vinda do Reino ao Brasil certamente mudou os padrões de desenvolvimento social e econômico com relação à época da Colônia, mas os benefícios não foram transformados de potenciais em reais na extensão da modificação institucional. Há sinais claros de uma insatisfação geral com o Estado, tanto antes da Independência, como na revolta de 1817 em Pernambuco, assim como após a separação do Império, que se pode verificar a partir de 1824 com o movimento republicano e secessionista da Confederação do Equador. A independência política em 1822 não foi acompanhada de independência econômica - os vários tratados desfavoráveis com a GrãBretanha entraram como moeda de troca numa duvidosa troca de favores, que foi o processo adotado de reconhecimento da emancipação nacional.

\section{Uma evolução social vincada pelo liberalismo econômico}

Na década mesma da Independência do Brasil havia reclamações por parte de representantes favoráveis a uma independência econômica e ao estabelecimento de indústrias no Brasil, como as externadas por Manuel Inácio de Melo e Sousa, presidente da província de Minas Gerais, justamente aquela onde se ensaiava com sucesso a tentativa de estabelecer uma indústria siderúrgica. Pode-se mesmo ver, ao menos em parte, a renúncia de Pedro I em 1831 como resultado de pressões nativistas e anti-lusitanas.

Em 1844 proclamou-se a Tarifa Alves Branco, que foi a primeira tentativa de orientar a política aduaneira em favor da indústria nacional, contrariando o liberalismo então vigente. Sua implantação enseja uma série de contradições, pois ora se fala de fomentar a indústria nacional, ora se refuta essa possibilidade (Carrara/ Meirelles 1996, I: 168-170). Embora houvesse anteriormente diversas manifestações a favor de uma política industrial, a aprovação em si dessa medida foi talvez mais um produto circunstancial para melhorar o balanço de pagamentos - e ela afinal acabou revogada pelo livre-cambismo das reformas de Souza Franco (1857) e Silva Ferraz (1860). Enquanto os países europeus e os EUA abandonavam (com protestos, 
é verdade) o modelo liberal da economia, em troca do intervencionismo estatal e do protecionismo aos seus produtos, o Brasil se tornava cada vez mais arauto do laissez-faire.

Em termos do papel do Estado, a política de D. João VI, que tinha um certo caráter intervencionista, poderia em princípio ter fomentado o desenvolvimento industrial, mas já referimos que, na prática, dela resultou um amplo compromisso com os interesses de exportação portugueses e as pressões dos ingleses. É certo que ela propiciou maior participação do Estado na vida econômica brasileira, mas longe de ser uma emulação em solo brasileiro das teses de Colbert sobre o mercantilismo e, principalmente, sobre o desenvolvimento das manufaturas.

A política econômica liberal adotada por Portugal com D. João VI causou problemas orçamentários, cobertos com empréstimos externos à Inglaterra, que se tornara desde 1810 a nação mais privilegiada no comércio com o Brasil. De fato, a Inglaterra era a nação mais favorecida com as tarifas alfandegárias do Brasil, especialmente após a abertura dos portos ao comércio internacional. Suas mercadorias pagaram durante quase todo o Primeiro Reinado apenas $15 \%$ de importação - as dos demais países pagavam 24\%, sendo mais baratas só para as portuguesas - e eram os ingleses praticamente os controladores da alfândega brasileira. Mais de metade da importação brasileira vinha da Inglaterra na época do início do Segundo Reinado.

Deve-se mencionar nesse contexto a total dependência financeira do país para com a Inglaterra, pois o simples reconhecimento de nossa independência política por Portugal (com mediação da Inglaterra) importou em o Brasil arcar com uma significativa dívida herdada de Portugal, o que condenou a nova nação a uma humilhante sujeição.

Toda essa influência inglesa era claramente manifestação de seu poderio econômico e militar, de que foi exemplo a pressão na abolição do tráfico de escravos. A Grã-Bretanha, que até pouco antes da proclamação da independência brasileira, auferia enormes lucros no tráfico de escravos africanos, mudou de posição e passou a reprimir esse comércio. As razões mais profundas para isto não eram naturalmente as apregoadas intenções humanitárias, que serviam para angariar simpatia pública, mas antes eram os próprios interesses britânicos. 
Produtos brasileiros concorriam com similares ingleses das Antilhas, devido à abundância da mão-de-obra escrava brasileira. Entre outros motivos ponderáveis que se pode arrolar para entender a posição britânica, destaque-se que o apresamento de navios pela marinha inglesa, transportassem ou não escravos, se transformava em operação de pirataria, com a apreensão de mercadorias valiosas que nada tinham a ver com o pretexto (Lima 1976: 237) ${ }^{1}$, pois era crescente a captura de navios comerciais brasileiros e portugueses e suas cargas, mesmo e principalmente as nãoescravagistas; por outro lado, os escravos apreendidos não eram libertados, mas abasteciam as colônias britânicas controladas pela Companhia das Índias Ocidentais (Prado Jr. 1974: 151-152).

Não é de estranhar portanto que, à vista de seu poder mundial, a quase totalidade das empresas estrangeiras instaladas no Brasil fossem britânicas. Num comportamento tipicamente imperialista, essas empresas importavam bens manufaturados e insumos, engenheiros e demais mão-de-obra; controlavam assim a infra-estrutura do país (minas, ferrovias, energia e comunicações), além de bancos e seguradoras. Por outro lado, a ideologia liberal adotada pelo governo brasileiro justificava essa submissão econômica ao capitalismo britânico.

Desconsiderando portanto o período de D. João VI pelas limitações apontadas, a citada tarifa Alves Branco é que foi uma primeira proposta de política industrial, embora originalmente voltada à recuperação do equilíbrio fiscal do comércio exterior. Pouco após sua promulgação, na Revolução Praieira em Pernambuco (1848) houve por parte dos revoltosos forte manifestação a favor da industrialização. Durante o Império praticamente foi este o último movimento armado com características de contestação ao regime, no que tange à base deste na aristocracia agrária e escravista (Mendes Jr. 1977,2: 263).

\footnotetext{
${ }^{1}$ Para uma boa exposição, ainda que ficcional, dos métodos e motivações reais dos britânicos a respeito da repressão à escravidão, veja-se o filme Queimada!, de G. Pontecorvo, onde o personagem de Marlon Brando retrata bem o oportunismo que uma hora levava a Grâ-Bretanha a apoiar um movimento abolicionista nativo para, em seguida, sufocar rebeliões dos mesmos pretos "livres".
} 
A defesa de um desenvolvimento industrial não foi portanto obra consistente de um pensamento articulado, como já destacaram analistas do fenômeno (p. ex. Luz 1975, cap. II). Até o último quartel do século XIX, há vozes mais ou menos isoladas, por mais valor que tivessem individualmente - e que surgiram mesmo desde antes da Independência, como José Bonifácio, quando clama ao Conde de Funchal, irmão e sucessor do conde de Linhares, que no Brasil "se removam os obstáculos da indústria, que a razão e as ciências ganhem pés diariamente" "2.

Outro exemplo característico das tendências vacilantes e pouco unidas do empresariado brasileiro foi a fundação da Sociedade Auxiliadora da Indústria Nacional, que começou a funcionar em 1828. Não obstante seu nome, tratava-se de instituição mais voltada para a agricultura, incluindo-se nela as ciências aplicadas à agricultura e a agro-indústria, assimilando portanto a idéia de uma "vocação agrícola" do Brasil. Atuando como consultora do Estado sobre a concessão de licenças, principalmente para a exploração de recursos naturais, era aquela no dizer de uma historiadora, "uma sociedade científica para uma sociedade agrária" (Domingues1996: 6). Essa característica da Sociedade Auxiliadora da Indústria Nacional só começa a se modificar lentamente e, com mais ênfase, a partir dos anos 80 .

Que não havia tampouco um pensamento articulado e coeso dos industriais, a própria Sociedade Auxiliadora da Indústria Nacional se encarregou por vezes de demonstrar, ao se posicionar contrariamente a uma política de industrialização do país, acatando as doutrinas liberais do laisser-faire. Não esteve portanto a classe empresarial à altura da oportunidade criada pela Tarifa Alves Branco - e nem seria esta a última vez que a burguesia brasileira demonstraria sua falta de personalidade própria. As exceções a esse quadro são novamente individuais, como o caso de Irineu Evangelista de Souza, futuro Barão e Visconde de Mauá, cujas empresas naufragaram por falta de um esquema financeiro de apoio - pela omissão do Estado e não pelo contrário, como tem sido propalado, por causa da intromissão estatal ${ }^{3}$.

\footnotetext{
${ }^{2}$ Carta de julho de 1813 a Domingos Antônio de Sousa Coutinho (Andrada e Silva 1998: 169).

${ }^{3}$ Como quer fazer crer Jorge Caldeira com sua biografia de Mauá, escrita sob medida para justificar o avanço do neo-liberalismo no Brasil da década de 1990 (Caldeira 1995).
} 
O Estado se ausentou da direção da economia mais notoriamente ainda durante o Primeiro Reinado, pela obediência absoluta aos princípios do liberalismo econômico. Basta observar que inexistia banco oficial, após a extinção do Banco do Brasil em 1829 - ao contrário dos EUA, onde um banco para financiar as nascentes indústrias nacionais já fazia parte das propostas dos federalistas (Hamilton 1995). O Banco do Brasil instituído por D. João VI em 1808 foi destinado a prover a manutenção da corte e não para fomentar a produção e as operações comerciais (Lima 1976: 150). Aliás, pode-se generalizar e afirmar que em todo o governo imperial não houve nenhum instrumento que pudesse financiar as atividades industriais, que exigem empréstimos de longo prazo e uma certa carência. O novo Banco do Brasil instituído em 1853 não cumpriu essa finalidade, nem tampouco os bancos privados. Alguns governos provinciais foram até mais condescendentes com suas indústrias do que o governo nacional, oferecendo-lhes diversos tipos de ajuda (Carrara/ Meirelles 1996, II: 500-507).

A partir de 1860 uma série de medidas de desregulamentação da ação estatal acabando com o pouco intervencionismo existente confirmaram a tendência de levar o país a se consagrar primordialmente à agricultura. Um momento de possível inflexão nessa diretriz ocorreu porém com a recessão econômica que atingiu os países industrializados por volta de 1875. Aliás, duas grandes guerras tinham por momentos criado condições mais favoráveis à industrialização brasileira: a Guerra Civil nos EUA (1860-65), que propiciou maior aceitação do algodão brasileiro no mercado internacional, e a Guerra do Paraguai (1865-70), que encareceu as importações brasileiras (Carrara/Meirelles 1996, II: 441).

O episódio que fez eclodir as insatisfações com a ausência de política industrial foi quando em 1874 a indústria chapeleira do Rio de Janeiro solicitou ao governo proteção tarifária em vista do assédio dos produtos importados. A Seção Comercial da Sociedade Auxiliadora da Indústria Nacional emitiu parecer contrário, assinado pelo engenheiro André Rebouças, que fez nessa ocasião verdadeira profissão de fé no liberalismo econômico. A Seção de Indústria Fabril da Sociedade Auxiliadora deu porém um parecer favorável à volta do protecionismo para incrementar a indústria nacional. 
Diversos setores da sociedade participaram da discussão, que foi terminada por um documento do presidente da Sociedade Auxiliadora, o também engenheiro José Maria da Silva Paranhos, Visconde do Rio Branco, que endossou a posição de André Rebouças, embora num tom de conciliação de defesa da vocação agrícola do país com algum desenvolvimento da indústria, desde que fosse voltado também para a agricultura (Carrara/ Meirelles, op. cit., II: 371-379).. Pode-se dizer que essa via de um desenvolvimento "gradual e lento" tem servido sistematicamente como desculpa para a ausência de medidas mais decididas em favor de uma real transformação social e econômica.

Em virtude desse conflito, os empresários mais afinados com o propósito do desenvolvimento nacional baseado na industrialização fundaram em 1882 na capital do Império uma outra organização, a Associação Industrial, liderada por Antônio Felício dos Santos. A depressão mundial e em particular a crise do café nos anos 80 foram favoráveis à maior industrialização e à reserva de mercado com substituição de importações propiciada a partir das novas tarifas de 1879. Os conflitos entre as correntes industrialistas e agrárias continuaram porém e engrossaram a fervura do caldo republicano, que pouco após conseguiria mudar a forma de governo.

Apesar do crescimento urbano verificado no período monárquico, o Brasil continuou como país cuja base eram as grande plantações - na primeira metade do período eram as fazendas de algodão e açúcar; na segunda metade, as fazendas de café. A indústria por seu turno era ainda muito incipiente para que pudesse vincularse a uma produção de saberes científicos, como vinha ocorrendo nos EUA e na Europa. Sendo a mentalidade das elites predominantemente agrícola e patriarcal, a sociedade como um todo pouco valorizava à ciência, exceto ocasionalmente por alguns resultados de fundo utilitário, como os voltados para a agricultura e a higiene pública (Stepan 1976: 40).

As culturas agrícolas que tradicionalmente fundamentaram a riqueza do Nordeste brasileiro foram porém decaindo ao longo do século XIX, em função de mudanças tecnológicas. Os avanços da química industrial européia levaram à criação do açúcar de beterraba, prejudicando as extensas plantações de cana da América. O algodão também sofreu com a concorrência da Ásia e mais ainda dos EUA, em que se 
empregava uma tecnologia avançada lá inventada, a do descaroçamento mecanizado. Por outro lado, no sul do Brasil se desenvolvia rapidamente a lavoura do café, mercadoria que vai sendo cada vez mais consumida e valorizada, especialmente no grande mercado consumidor dos EUA após sua independência (Prado Jr 1974: 157-167). Como no restante da agricultura brasileira, esta é uma atividade que desemboca no latifúndio, dominado pelas oligarquias; a diferença é que nas plantações de café se introduz com vigor, já no final do Império, a mão-de-obra imigrante, no lugar da escrava.

Nota-se também que durante bastante tempo, enquanto se espalhava pelo vale do Paraíba, foi praticada uma agricultura cafeeira com pouca ou nenhuma ciência, acarretando terras desgastadas, plantações fracas e sujeitas a pragas. Devido a isto, bem como naturalmente à crescente produção cafeeira, houve uma expansão constante da fronteira agrícola. Quando se deslocaram as culturas para o oeste paulista, principalmente após a Guerra do Paraguai, é que são introduzidas pela primeira vez em nosso solo as máquinas agrícolas, tais como ventiladores, despolpadores e aparelhos de burnir e separar o café (Lima 1976: 232).

O mercado interno brasileiro ao longo do período monárquico não pode ser estimado com precisão. Sabe-se que o nível de renda anual (de 3 a 4 libras esterlinas por habitante) era muito baixo para os padrões da época; só no final do Império começou a existir uma classe média com um pouco mais de relevo, mas isto permanecerá sendo (e ainda o é, em nossos dias) uma pedra de tropeço para o desenvolvimento da indústria nacional.

De fato, a falta de um mercado amplo de consumo tem feito com que a grande massa da população brasileira não tenha acesso a mercadorias geradas pela indústria - durante boa parte da história brasileira as importações substituem a produção própria por terem menor preço; por outro lado, o fabricante brasileiro, voltado para a mentalidade elitista e viciado por um viés de mercantilismo á maneira dos portugueses, tipicamente prefere sempre vender um único bem muito mais caro do que outros tantos produtos mais baratos.

No Brasil, o predomínio dos latifúndios e das grandes empresas contrasta nitidamente com os EUA, onde os pioneiros criaram ao longo do século XIX uma extensa rede de pequenas e médias propriedades, resolvendo o problema a posse 
da terra e gerando uma classe e um mercado interno que puderam absorver boa parte da expansão econômica e impulsionar as manufaturas.

A extinção do tráfico internacional de escravos para o Brasil em 1850 acabou por mostrar um flanco fraco da agricultura brasileira do Império, justamente sua enorme dependência da mão-de-obra escrava. Intensifica-se então o movimento de imigração de europeus e asiáticos, relativamente fraco por bom tempo, mas que se acelera muito a partir da década de 1880, concomitantemente com a maior presença industrial na economia. Por outro lado, o capital que antes era empregado no tráfico é desviado na segunda metade do século para outras atividades comerciais e, em menor escala, industriais.

Nota-se também no final do Império o crescimento das correntes migratórias internas, especialmente após a grande seca do final da década de 80, em que as populações nordestinas demandaram a região amazônica (em função da borracha), o sul da Bahia (devido à lavoura do cacau) e sobretudo São Paulo, cujo crescimento agrário era acompanhado de um florescente comércio e de diversas manufaturas, criando um proletariado significativo (Prado Jr. 1974: 202).

O progresso econômico da segunda metade do Império fez com que, além das camadas das classes dominantes, crescesse o proletariado rural (colonos) e urbano (operários, ferroviários, caixeiros, etc.), bem como uma tímida classe média (pequenos comerciantes, funcionários públicos, operários mais qualificados) - e esta última é que iria fornecer cada vez mais os oficiais militares, o clero e os novos profissionais liberais.

\section{0 ambiente cultural}

Além de importar mercadorias manufaturadas, a importação de idéias foi também bastante característica da vida imperial brasileira, nem sempre com propriedade. As idéias típicas do liberalismo de Adam Smith foram divulgadas em Portugal e no Brasil por Cairu, que defendia que as indústrias mais convenientes para o povo brasileiro seriam aquelas associadas à agricultura, comércio e navegação - basicamente visando impedir o nascimento de uma indústria têxtil, o que contrariaria a Grã-Bretanha. Coerentemente com sua posição liberal, Cairu previa que o Estado só tutelasse a economia e não que fosse o indutor do desenvolvimento (Carrara/Meirelles 1996, I: 157-158). 
Além do liberalismo, importado da Grã-Bretanha, vieram da França três influências que repercutiram bastante no ambiente cultural brasileiro: o positivismo, o espiritismo (de Kardec) e a homeopatia (Alencastro 1997: 44). O positivismo de Comte começou a se difundir no Brasil na década de 1840. Após o fim da Guerra do Paraguai (1870), idéias cientificistas se propagaram mais rapidamente, em consonância com as mudanças sociais ligadas à produção cafeeira, que passava a usar a mão-de-obra imigrante ao invés da escrava, e as pressões internacionais das políticas imperialistas, que preconizavam a integração do Brasil na divisão de trabalho internacional.

Havia portanto manifestações culturais que se associavam a uma base material começando a acenar com impulsos de modernização. Os positivistas brasileiros apoiaram o sistema republicano e o fim da escravidão, atacando a monarquia e a Igreja Católica. A monarquia era vista como continuadora da tradição colonialista, ligada à estrutura agrária e à escassa oportunidade de educação secundária e universitária dos brasileiros.

Um famoso sábio suíço-americano, Louis Agassiz, após visitar o Rio de Janeiro, escreveu em 1868 que os estabelecimentos de cunho científico brasileiro eram mal aparelhados e os naturalistas brasileiros não se interessavam pelo trabalho experimental, preferindo o conhecimento livresco por influência da escravidão, o que levava ao desprezo pelo trabalho feito com as mãos (Stepan 1976: 42).

É inegável a influência política de professores positivistas nas escolas superiores brasileiras, como Benjamin Constant e Álvaro de Oliveira. A parte científica do comtismo foi afinal ultrapassada e não deixou de ser criticada no devido tempo aqui no Brasil; por este motivo, não se poderia imputar exclusivamente ao positivismo a culpa pelo atraso científico no país ${ }^{4}$.

Por outro lado, acreditamos que a influência deletéria do positivismo entre nós foi grande, e ultrapassa de longe sua vertente científica. Isto transparece quando se considera sua proposta filosófica e epistemológica como inscrita na tradição tanto do empirismo

\footnotetext{
${ }^{4}$ Maria Amélia Dantes - em "Os Positivistas Brasileiros e as Ciências no Final do Século XIX" (Hamburger et alii, 1996: 49-63) - faz uma análise da produção científica dos positivistas brasileiros, concluindo pela sua importância relativamente reduzida.
} 
inglês quanto do pensamento kantiano. Estes se caracterizam pela crença na eficácia apenas dos resultados e pelo abandono das perguntas causais mais profundas, desconsideradas sob a pecha de serem metafísicas. A posição das elites brasileiras vem sendo marcada desde o Império até nossos dias justamente por esse tipo de visão de curto alcance, evidente quando se vê sua preocupação com o imediatismo de seus lucros e não com a disseminação da educação e a distribuição de terras e rendas - que a longo prazo geram multiplicativamente montantes de lucros ainda maiores.

Observa-se ainda que há uma tendência antiga em parte da historiografia do Império, a de exaltar o papel de D. Pedro II como mecenas das ciências, técnicas e artes. Cremos que ainda que assim fosse - e ele o foi muitas vezes, sem dúvida - é preciso lembrar que seu esforço foi geralmente isolado, sem criar nenhuma política mais duradoura nesse sentido. D. Pedro II, apesar do interesse pessoal por questões dessa natureza, praticamente nada fez para atacar o problema de uma forma social, limitando-se a pouco mais do que patrocinar indivíduos em carreiras científicas ou artísticas. A própria vida pública do imperador foi marcada por contradições notáveis e oscilações, mas o que interessa de fato do ponto de vista social é a pequenez de resultados concretos. Um exemplo disso é que nenhuma universidade foi fundada no Brasil antes do século XX.

Ainda sobre esse tema, lembramos que num momento decisivo da vida do Império, no início da década de 70, o imperador deixou-se influenciar fortemente pela ideologia do Conde de Gobineau, então embaixador da França no Brasil. Este era o autor do "Ensaio sobre a Desigualdade da Raças Humanas", marcadamente racista e que defendia a supremacia ariana, chegando a repercutir em Nietzsche e Wagner. Neste ensaio Gobineau ataca a mestiçagem no Brasil e de certa forma justifica a escravidão de uma raça por ele considerada inferior, recomendando que o governo brasileiro atraísse imigrantes alemães (Raeders 1988) ${ }^{5}$.

Apesar das limitações mencionadas, as elites políticas do Império seriam, na visão do historiador José Murilo de Carvalho, responsáveis pelo fato louvável de o Brasil não ter se sub-dividido, como ocorreu na América Espanhola (Carvalho 1980), concorrendo

\footnotetext{
${ }^{5}$ Vale a pena consultar nesta obra o texto de Gobineau sobre o Brasil de 1873 (215-252).
} 
para isto o governo ter sido civil e não militar, com reduzidos conflitos. Isto é por ele atribuído ao seu treinamento - na primeira metade do século XIX tratava-se de uma elite política formada em Coimbra, hábito aliás que vinha da era colonial - e de uma unidade ideológica, graças às tradições do mercantilismo e absolutismo portugueses. Essa elite, ainda segundo Murilo de Carvalho, não representava, obviamente, nem a maioria da população, nem as próprias classes dominantes, o que apressou seu fim na medida que foi sendo substituída por profissionais liberais, particularmente os advogados, mais capazes de articular os interesses regionais e de classe.

Essa explicação é engenhosa, mas um pouco exagerada, pois ignora justamente o papel das transformações sociais induzidas pelo progresso técnico e que se tornavam incompatíveis com a "ordem" imperial. Afinal republicanos e monarquistas não eram assim tão diferentes, sendo melhor descritos como os paradigmáticos e antagônicos irmãos Pedro e Paulo - "Esaú" e "Jacó" - criados em romance por Machado de Assis - no fundo intercambiáveis pois as continuidades superam as contradições - e afinal oriundos duma mesma "família".

Parece-nos ainda que a linhagem citada acima da corrente mercantilista vai mais longe porque repousava diretamente no liberalismo britânico nos moldes de Adam Smith, um escritor que incidentalmente admitia o escravismo e defendia um Estado menos cerceador - apesar de na verdade ser o Estado que garantia todos os privilégios aos comerciantes e exportadores.

A formação superior que, com as escolas de engenharia ( mais do que qualquer outra profissão), permitiu entrar diretamente em contato com o processo de modernização por que passavam os EUA e a Europa, era uma conseqüência das referidas transformações sociais e ao mesmo tempo um desejo de diminuir as distâncias que nos separavam desses países. Perguntamos enfim se tais anseios foram compreendidos pelas elites imperiais e igualmente pelas republicanas - ou se os móveis das transformações se deram pelas influências externas, através de imigrantes, ou de contatos com o exterior, bem como pelas crises de exportação - já que apesar das fracas políticas industrializantes, houve significativa substituição de importações na segunda metade do Império, o que ocorreu esporadicamente também durante a nova República. 
Importa ainda considerar que o liberalismo que em geral se impôs no Império pode ser contrastado com os EUA, em que idéias como as de Alexander Hamilton levaram a uma intervenção do Estado (Hamilton 1995), garantindo proteção efetiva para as indústrias nascentes, sob a inspiração de uma burguesia urbana, ao contrário do Brasil com o predomínio de setores agrários.

Uma exceção a esse quadro geral foram as já referidas revoltas da Confederação do Equador e da Revolução Praieira. Nesta houve inclusive alguma disseminação de idéias socialistas, trazidas por um engenheiro, o francês Louis Vauthier, contratado como Diretor de Obras de Pernambuco e introdutor de diversas melhorias urbanas em Recife. Sua pregação de socialismo, baseada em Fourier e Louis Blanc foi porém mal compreendida e assimilada, e no contexto da época se tornava dificilmente aplicável contra o latifúndio e a oligarquia nordestinos (Mendes Jr. 1977: 265-267).

Do ponto de vista da luta contra as idéias mais retrógradas e obscurantistas, é verdade que com a vinda de D. João VI, aos poucos se incentivou alguma liberdade literária e de opinião, como evidenciado pelo jornalismo de Hipólito José da Costa e seu "Correio Brasiliense". Mas trata-se de uma produção de relativa pouca circulação. Só bem mais tarde surgem veículos informativos de maior circulação, como o Jornal do Comércio no Rio e em terras paulistas A Província de São Paulo.

É também progressivamente que durante o Império o lazer se dissemina. O teatro lírico passa a ser diversão que atrai não só as classes dominantes, e o mesmo ocorre com o teatro de revista, o carnaval, as regatas, os restaurantes. A mulher finalmente sai à rua para fazer compras (Lima 1976: 274). Os problemas sociais saem das ruas e são retratados na literatura, a princípio apoiados em diversas vertentes da ideologia nacionalista, mas acabam por transcender essa dimensão, como nos contos e romances de Machado de Assis, nos romances urbanos de Joaquim Manuel de Macedo e Manuel Antônio de Almeida. As peças teatrais de Martins Pena refletem uma oposição cidadecampo e ironizam o cotidiano monárquico - cada vez mais expondo a figura do 
imperador, como deixam claro os escândalos amorosos de Pedro II ${ }^{6}$, cuja figura impulsiona a crítica de costumes e as caricaturas de Agostini.

Castro Alves traz o tema da abolição para a poesia, e se torna imediatamente popular (como talvez nenhum outro poeta brasileiro o foi). No meio urbano florescem as modinhas, antes associadas apenas à aristocracia rural da casa de fazenda, assim como os choros, indicativos de transformações por que passava o Brasil, onde as classes populares passam a assinalar sua presença. Um historiador destaca que a mercadoria-fetiche para várias classes do $2^{\circ}$ Império será o piano (Alencastro 1997: 45-47), de início para possibilitar o mimetismo da modernidade européia, para depois servir de meio de criação para a música popular. O piano se soma assim aos móveis importados que vêm substituir os produtos coloniais - embora estes na sua tosca feitura às vezes fossem mais adequados que os novos.

Da nova classe média formada na segunda metade do Império saem médicos e engenheiros, profissionais que ganham cada vez mais prestígio e serão instrumentais para o esforço de modernização. Mesmo pensadores com tendências conservadoras como Tobias Barreto se abrem para idéias novas, que pregam a renovação social e cultural (Barreto 2001); e assim o republicanismo ganha cada vez mais adeptos, preparando a mudança do regime.

\section{Criação da Infra-Estrutura e a Industrialização}

Ao longo do período monárquico assinalam-se investimentos essenciais na infraestrutura do país, sem entretanto perdermos de vista as mencionadas insuficiências para uma transformação essencial das estruturas, inadequadas para vencer o anacronismo científico-tecnológico e prover um conjunto maior da população dos bens necessários, ou ao menos para criar uma classe média ponderável. Por infra-estrutura entenderemos aqui os setores de transporte, saneamento básico, energia e comunicações.

\footnotetext{
${ }^{6}$ Veja-se o caso do roubo das jóias imperiais, nas versões (presumidas) de Raul Pompéia, Artur Azevedo e José do Patrocínio, reproduzidas em Pompéia (1993).
} 
Dentre os avanços pode-se citar seguramente o das ferrovias. Há iniciativas antigas, como mostra a proposta de concessão assinada pelo regente Diogo Antônio Feijó para construir estrada de ferro em 1835, ligando o Rio de Janeiro a Minas Gerais, Rio Grande do Sul e Bahia. Há várias outras propostas na primeira metade do século, também sem sucesso. A primeira ferrovia concretizada seria bem pequena, entre o fundo da Baía de Guanabara e até o sopé da Serra de Petrópolis, construída por Mauá (seu primeiro trecho foi inaugurado em 1854 e o trecho final em 1856), a partir de estudos de engenheiros ingleses. Seguem-se-lhe alguns trechos da Estrada de Ferro D. Pedro II, para Minas e São Paulo, cujo projeto já conta com engenheiros brasileiros, muitos deles sem a respectiva instrução teórica, mas treinados na prática da construção da própria estrada (Telles 1994, cap. VI). Há até um plano, não executado, feito pelo engenheiro militar Cristiano Ottoni, que previa integrar todo o território nacional por meio de ferrovias.

Uma grande necessidade a ser suprida pelas ferrovias era o transporte de mercadorias e de possíveis produtos pesados como os siderúrgicos. No entanto, as primeiras estradas de ferro em geral não foram bem sucedidas comercialmente, pois não atendiam a referida demanda, além de exibirem defeitos técnicos decorrentes da falta de planejamento e estudos adequados. As estradas de ferro brasileiras foram construídas com grande diversidade de bitolas, o que se deveu a serem empreendimentos feitos por companhias britânicas, com a preocupação de aproveitar material ocioso provindo de várias partes do Império Britânico.

A multiplicidade de bitolas foi um fator inibidor da consolidação de um parque industrial ferroviário nacional, não obstante esforços dos estaleiros navais nesse sentido; mais tarde, na República, seria também esse o principal obstáculo para a criação de malha ferroviária realmente integrada, não só no território nacional, mas também com os países vizinhos. A este problema se somou o do mau traçado, após o decreto de subvenção governamental, de 1873, que privilegiava as estradas construídas pelos caminhos mais tortuosos e íngremes .

\footnotetext{
${ }^{7}$ O engenheiro Christiano Ottoni já prevenira contra isto num livro precursor, O Futuro das Estradas
} de Ferro no Brasil, de 1859 (cf. Telles 1994: 392). 
As estradas de ferro serviram como formadoras da engenharia brasileira muito para além do Império, mantendo esta característica pelo menos até o final da República Velha. Acrescente-se a esta a função de ser nesse período o grande mercado empregador de profissionais e operários livres. Um problema não resolvido pelas ferrovias nacionais foi o da fonte energética: carvão importado caro ou carvão nacional de baixa qualidade, ou ainda então tração a lenha, que exigia um desmatamento formidável quando na Europa na década de 1880 os alemães já introduziam a locomotiva elétrica.

O declínio da produção de açúcar e algodão e, a partir da década de 1830, a ascensão do café, plantado cada vez mais no interior, é que obrigaram a melhorar os transportes de mercadorias exportáveis. Isto se dará numa segunda fase de construção ferroviária, principalmente na que se tornaria a grande província cafeeira, São Paulo. Surgiu assim a “São Paulo Railway” (a Estrada de Ferro Santos-Jundiaí), de capital inglês, inaugurada em 1867 (com a inovação técnica de tração funicular), seguida por outras estradas: Paulista, Ituana, Sorocabana, Mogiana e Noroeste, todas em direção ao oeste paulista. As suas oficinas de manutenção acabavam por industrializar determinados itens, como rodas feitas com ferro nacional, embora sem propiciar nenhum desenvolvimento tecnológico, pela inexistência de indústrias de base a elas associadas ${ }^{8}$.

Como nos EUA e na Europa, a disseminação das estradas de ferro foi associada à chegada de uma civilização mais moderna, propiciada por empresas capitalistas mais avançadas do que as tradicionais plantações com base no trabalho escravo. Além disso, elas trouxeram uma valorização de profissões menos bacharelescas, como a do engenheiro e do mecânico, exemplos de trabalho livre e qualificado. $\mathrm{O}$ crescimento do transporte de passageiros, além da carga, atesta o rompimento lento do isolamento das províncias; isto se dava não só pelo transporte em si, mas também pela concomitante construção de linhas telegráficas ao longo das ferrovias. Ao final do Império havia cerca de $9.500 \mathrm{~km}$ de estradas de ferro em operação.

\footnotetext{
${ }^{8}$ É o que ressalta Júlio R. Katinsky - "Ferrovias Nacionais” (Motoyama 1994).
} 
Quanto ao transporte por estradas de rodagem, até o início do século XIX elas eram caminhos de terra precários, com exceção de alguns trechos calçados com pedras, bons para tráfego de animais e carroças ou, mais propriamente, tropas de mulas e carros de bois. Em 1835, Minas Gerais promulgou lei estabelecendo um plano rodoviário regional, já com alguns requisitos técnicos, como largura e declividade máxima (Telles 1994: 206). Uma importante estrada surgiria em decorrência (1838), feita pelo engenheiro alemão Henrique Halfeld, ligando Ouro Preto ao Rio Paraibuna, aonde surgiu a cidade de Juiz de Fora.

Na segunda metade do século apareceram as primeiras estradas de rodagem macadamizadas e com requisitos mais modernos de declividades, raios de curvatura e drenagem ${ }^{9}$, como a "União e Indústria", de Petrópolis a Juiz de Fora (1860), já com a colaboração da engenharia brasileira, e no Paraná a estrada da Graciosa, entre Antonina e Curitiba, vencendo a Serra do Mar (1873). Em ambas era possível o tráfego de diligências, o que porém durou pouco tempo, devido à concorrência das ferrovias, resultando que as poucas estradas macadamizadas foram se deteriorando. Esta situação só se alteraria após a consolidação do transporte em automóvel, em meados da República Velha.

As instalações portuárias não passavam de trapiches que não permitiam atracação direta. A introdução da navegação a vapor ensejou o desenvolvimento do comércio marítimo e fluvial e, em especial, induziu à melhoria dos portos. A partir da década de 1860 foram realizados melhoramentos essenciais no porto do Rio de Janeiro. Ali foram empregados na construção das fundações pela primeira vez no país o cimento tipo "portland" e o escafandro, sob a orientação do engenheiro André Rebouças (Telles 1994: 333). Mesmo assim, durante o Império a maioria dos navios ainda fundeava longe do porto, havendo necessidade de transbordo de passageiros e cargas para embarcações menores. Santos, apesar da pressão decorrente do transporte de café pela ferrovia Santos-Jundiaí, terá seu novo porto apenas no início do período republicano; caso análogo ocorreu com o porto da Barra do Rio Grande, na

\footnotetext{
${ }^{9}$ Milton Vargas - “Construção de Estradas” (Motoyama 1994: 137-140).
} 
saída da Lagoa dos Patos, projetado por engenheiros brasileiros do tempo do Império, mas efetivamente construído no século XX.

Uma última palavra sobre os meios de transporte diz respeito aos transportes públicos urbanos. No início do período monárquico a base destes eram as diligências, as "gôndolas" (Telles 1994: 370), mais tarde substituídas por bondes sobre trilhos, puxados a burros. Na década de 1860 introduziu-se a tração a vapor com as pequenas locomotivas chamadas de "maxambombas" (corruptela de "machine pumps").

Na questão do urbanismo e das construções, lembramos que houve renovação da arquitetura com a chegada em 1816 ao Rio de Janeiro da Missão Artística Francesa. Ela incluía pessoas talentosas como Debret, Taunay e o arquiteto Grandjean de Montigny e teve como desdobramento a criação em 1820 da Academia de Desenho, Pintura, Escultura e Arquitetura Civil. Os costumes também mudaram com a vinda da Corte, como se vê pela proibição (1809) de treliças, rótulas e muxarabiês, talvez para possibilitar o uso em grande escala dos vidros ingleses, além da vulgarização do uso do ferro (Telles 1994: 125). Outras modificações ocorreram nas fachadas e telhados, bem como no estilo neo-clássico, que se tornaria característico das grandes edificações no Império.

Na segunda metade do século XIX, especialmente fora do litoral, a taipa começou a ser substituída pelo tijolo, material que também demonstrou muita utilidade nos terreiros e tulhas de café, acompanhando essa riqueza crescente tanto nas áreas rurais quanto urbanas (Lemos 1989: 39-43). Em São Paulo, a construção civil ficou em mãos de mestres e artesãos italianos, de que resultou um estilo mais eclético do que na Corte. A partir de 1880, surgiram posturas municipais e projetos específicos para habitações proletárias, para tentar impedir a disseminação de cortiços.

Ao final do Império se acelerou a construção com elementos metálicos e muitas vezes a edificação inteira vinha pré-montada da Europa (como por exemplo o Mercado de Manaus, a estação ferroviária de Bananal e o viaduto do Chá em São Paulo). A importação era uma saída, devido ao atraso da siderurgia brasileira, pelo que aquelas obras representavam o moderno, a construção rápida com conforto e higiene (Costa 1994: 11). 
A arborização das cidades, que não era praticada na Colônia, foi intensificada na segunda metade do século XIX, por influência francesa. Em São Paulo, a partir da década de 70 são formados novos bairros, tanto para a classe alta (Campos Elíseos, Higienópolis) quanto para as novas classes trabalhadoras, cuja maioria era de imigrantes. Há melhoramentos também em outras cidades das províncias, como Recife, e ainda a planificação de outras, como Petrópolis e Valença no Rio de Janeiro, e Teresina e Aracaju no Nordeste (Telles 1994: 152).

Sem contar o antigo sistema de levar água por encanamentos até chafarizes, de que são exemplos os aquedutos romanos e entre nós o dos arcos de Santa Teresa, no Rio de Janeiro, a então capital imperial teve a primeira rede pública de distribuição de água inaugurada na década de 1870, servindo cerca de 8.000 edificações. Da mesma época é o sistema adutor da Cantareira, em São Paulo, para 3.000 edificações. Nos anos 70 e 80 diversas outras cidades brasileiras recebem alguns serviços de água encanada.

Recorde-se ainda que no Império começou a "indústria da seca”, com a construção dos açudes como o de Quixadá, iniciado em 1884 e concluído no início da República. Houve também casos isolados de melhoramentos em rios e construção de alguns canais para navegação.

Era comum a contratação de empreiteiras inglesas para realizar tais serviços hidráulicos, que redundaram também nas primeiras redes públicas de esgotos. Essas melhorias vieram a ser reclamadas desde que a partir de 1850 a capital imperial foi assolada por surtos constantes de febre amarela. Os manguezais e terras alagadiças começaram a ser transformados em terras aproveitáveis para urbanização ainda no tempo colonial, e extensões maiores como a higienização do Mangue carioca (iniciativa de Mauá) datam também da década de $1870^{10}$. Recife foi a segunda cidade brasileira a ter rede de esgoto, seguida por algumas outras cidades - o que não causa espanto sabendo-se que até hoje, ao final do século XX, a maioria da população

\footnotetext{
${ }^{10}$ Milton Vargas, “Obras de Saneamento (Abastecimento de Água, Esgotos e Recuperação de Terras)” (Motoyama 1994: 85-88).
} 
não tem serviços sanitários de esgoto, que nossos rios urbanos são vergonhosas cloacas a céu aberto e que quase não dispomos de tratamentos secundários e muito menos terciários do esgoto coletado.

Até a primeira metade do século XIX, a iluminação pública era precária e o uso do gás começou no Rio de Janeiro em 1854, com material fabricado na empresa do Visconde de Mauá (Estaleiro de Ponta d'Areia). A iluminação pública de ruas e parques da cidade, onde se pôde então passear até de noite, permitiu que se desenvolvesse uma vida social mais movimentada. Pouco após, começaram as experiências de iluminação elétrica, sendo o primeiro edifício a contar permanentemente com esse benefício a Estação Central de trens do Rio de Janeiro, em 1879, com dínamos acionados a vapor. A cidade pioneira em iluminação pública elétrica foi Campos, no Rio de Janeiro, em 1883, seguida por Rio Claro (São Paulo) no ano seguinte. Ainda na década de 80 iniciou-se no Brasil o aproveitamento hidro-elétrico, em Minas Gerais, usando-se a eletricidade gerada para força motriz na mineração, destacando-se ainda a usina de Juiz de Fora para iluminação pública e acionamento da fábrica de tecidos de Bernardo Mascarenhas.

O primeiro telégrafo nacional foi inaugurado em 1852 no Rio de Janeiro e esse meio de comunicação foi paulatinamente se espalhando pelo território nacional ${ }^{11}$, principalmente a partir das necessidades decorrentes da Guerra do Paraguai. Ao final do Império a rede telegráfica cobria todo litoral e se ligava aos países vizinhos do sul. O cabo submarino entre o Brasil e a Europa foi inaugurado em 1874, por iniciativa do Visconde de Mauá.

Passamos agora a traçar um rápido esboço do quadro industrial brasileiro do Império. As indústrias têxtil e a metalúrgica representavam na primeira metade do século XIX os setores mais avançados dessa atividade econômica. No entanto, a produção têxtil nacional permaneceu muito inferior à do material importado, descontando-se a produção mais artesanal e os tecidos grosseiros.

\footnotetext{
${ }^{11}$ Gildo Magalhães - “Telecomunicações” (Vargas 1994).
} 
Após a reforma tarifária de Alves Branco, aumentou a produção têxtil de algodão, mas poucas indústrias prosperaram antes da década de 80; algumas, inclusive, substituíram a roda d'água pelo vapor e foram inicialmente projetadas por ingleses mas a partir de 1880 também por engenheiros brasileiros. Quando se conseguiu a integração da produção (desde o fio até o tecido acabado, passando pelo alvejamento e tinturaria) é que as indústrias têxteis tornaram-se o setor industrial mais importante do país, ao lado da siderurgia.

No que diz respeito à atividade metalúrgica, além da siderurgia (de que trataremos adiante), cabe mencionar o Estaleiro de Ponta d'Areia, em Niterói, comprado em 1846 por Mauá, e que foi o complexo industrial mais importante do Império. Ali, além de navios, se fabricavam caldeiras, máquinas a vapor, vagões ferroviários, guindastes, serrarias e outras máquinas (Telles 1994: 176-182). O estaleiro foi vendido por Mauá em 1870, devido às suas conhecidas crises financeiras, sendo definitivamente fechado em 1888.

Outras indústrias que chegaram a ter importância econômica durante o Império foram as de:

- chapéus (ter chapéu nacional chegou a ser símbolo de nacionalismo na década de 1830);

- alimentos (chocolates, massas e farináceos);

- couros (usando-se o tanino do mangue para curtir as peles);

- vidros, com a pioneira fábrica de Ubatuba, em São Paulo, mais tarde transferida para o Rio de Janeiro; a indústria brasileira não produzia vidros planos e se dedicava mais a objetos como garrafas;

- papel, de baixa qualidade, para embrulho e papelão;

- pólvora (em geral com salitre importado) e outros explosivos, especialmente após a Guerra do Paraguai;

- fósforos;

- gás de carvão ou de derivados de petróleo, produzido em gasômetros, para iluminação; 
- óleos vegetais (mamona, rícino, coco, amendoim, algodão);

- adubos orgânicos de origem animal e vegetal; em contraposição, foi incentivada a importação de adubos químicos para ajudar na crise da agricultura após a abolição da escravatura;

- inseticidas, principalmente a partir da descoberta pelo engenheiro Gustavo Schuch, barão de Capanema, do uso do sulfeto de carbono como formicida eficaz contra a saúva;

- sabão e velas (de esparmacete ou estearina, mas em geral de sebo), setor industrial de grande dinamismo no Brasil, com produtos de qualidade comparável aos importados ${ }^{12}$;

- alguns insumos químicos, como álcool (etanol, obtido da cana de açúcar) para iluminação; observe-se porém que as primeiras fábricas de ácido sulfúrico, fundamental para a indústria química como um todo, só foram instaladas na década de 1880, após quase meio século de debates infrutíferos e que atestam o desprezo de intelectuais e políticos para com questões tecnológicas (Carrara/Meirelles 1996, II: 810-834).

Para a construção civil foi importante o nascimento da indústria de cimento no país, que se inicia ao final do período monárquico em 1888, na fazenda Santo Antônio na estação de Alumínio, perto de Sorocaba, Estado de São Paulo. A cal, que era explorada rudimentarmente em vários locais desde o século da descoberta, também por essa época passa a ter os primeiros fornos contínuos na região de Santana do Parnaíba, São Paulo.

A partir de 1870 modernizou-se a indústria açucareira, com as usinas centrais que substituíram os antigos engenhos. É o exemplo clássico da "modernização sem mudança" de que fala Peter Eisenberg, pois pouco afetou as relações sociais existentes (Eisenberg 1977).

As exposições universais, continentais e mesmo nacionais serviram principalmente no século XIX e início do século XX como vitrinas do modo de produção capitalista, que por excelência se prestava à internacionalização tanto no aspecto de trocas quanto no imaginário popular, papel este assumido em nossos dias pelas

\footnotetext{
${ }^{12} \mathrm{Cf}$. a quadrinha comercial de Olavo Bilac: Vencida e em trevas sepulta/ Morde-se a indústria estran-
} geira/ Pátria independente, exulta:/ Tens a Vela Brasileira"(cit. em Carrara/Meirelles 1996, II: 749). 
inúmeras "feiras" industriais e comerciais. Nas exposições do século XIX falavase já então na "indústria moderna”, que nelas se fazia representar - e o Brasil, pelo menos em certos setores mais esclarecidos, certamente aspirava representar uma parte no espetáculo dessa modernidade (Pesavento 1997: 60). Se não era moderno, ao menos o país deveria parecer "civilizado" para os demais países e impor uma imagem dissociada das febres e cobras caricaturais.

No total, no Brasil durante o Império houve cinco exposições nacionais (1861,1866, 1873, 1875 e 1889) e uma exposição industrial (1881); o país participou das exposições internacionais de Londres (1862), Paris (1867), Viena (1873), Filadélfia (1876) e Paris (1889).

A Exposição Nacional de Produtos Naturais e Industriais de 1861 no Rio de Janeiro contava com maioria de produtos naturais e artesanais. Seus organizadores enfatizavam que a modernidade pretendida era a agrária e não a fabril. Em conseqüência havia poucos produtos industriais verdadeiramente nacionais (Telles 1994: 190). Dentre estes se destacava a máquina a vapor para navio de $200 \mathrm{cv}$, fabricada no Arsenal de Marinha, bem como produtos do estaleiro de Ponta d'Areia. Já em 1881, na Exposição da Indústria Nacional, também no Rio de Janeiro, havia algum progresso com relação à de 1861, em termos de quantidade de produtos. Destacavase igualmente a produção naval, com máquina a vapor de $2.200 \mathrm{cv}$, além de produtos ferroviários das oficinas da Estrada de Ferro D. Pedro II e muitas máquinas agrícolas (principalmente para beneficiar café). Na Exposição Universal de 1889, o Brasil enviou junto com outros itens produtos da indústria metal-mecânica, química e farmacêutica, material elétrico e máquinas (Pesavento 1997: 195).

Das Ciências e das Técnicas

O Museu Real (mais tarde Museu Nacional), criado em 1818 no governo de D. João VI, dedicou-se basicamente à História Natural, que incluía a mineralogia e as ciências naturais. Como a História Natural não dependia de treinamento sofisticado, constituía um dos poucos setores em que a ciência brasileira podia crescer, e além de receber contribuiçõos empíricas de amadores havia uma crença de que seus resultados fossem úteis para a sociedade. 
Em conseqüência, diversos viajantes nacionais e estrangeiros fizeram um amplo levantamento do território nacional durante o período monárquico e recolheram minerais, espécimes vegetais e animais, organizando coleções que, no fundo representavam uma forma de pesquisa de matérias-primas e fontes energéticas no território nacional (Figueiroa 1997: 71). Esta pesquisa foi feita atendendo tanto interesses brasileiros quanto de nações européias, sendo seus resultados enviados para o Museu Real ou para os países financiadores das expedições.

São também indicativos do interesse pela História Natural a fundação de algumas sociedades dedicadas ao assunto, como a Sociedade Velosiana de Ciências Naturais (1850) e a Palestra Científica (1856). Pesquisas mais recentes vêm apontando o papel dos museus na institucionalização das ciências naturais no Brasil, inclusive como auxiliares daquelas primeiras sociedades científicas (Lopes 1997). O Museu Nacional, ao invés de unicamente estudar fauna, flora e minerais brasileiros, propunhase funcionar como um museu global, nos moldes europeus, contribuindo para as pesquisas e a divulgação em biologia, química, física, antropologia e geologia durante o Segundo Reinado; para isto contava com laboratório de análises adequado. Nas províncias, os museus eram mais localmente especializados. Esses desenvolvimentos ocorriam não obstante a falta de prioridade que as ciências como um todo tinham no contexto político-econômico do Império.

Numa atividade com pontos de semelhança com as dos naturalistas, engenheiros militares tiveram no Império a missão de demarcar fronteiras do Brasil com seus vizinhos, além de levantar os cursos e potenciais dos rios - neste caso com o concurso de vários engenheiros civis brasileiros e estrangeiros.

Dentre as ciências ditas básicas, como a física e a química, pouco se podia fazer no Brasil. Dados sobre o clima e observações astronômicas no Rio de Janeiro começaram a ser registrados regularmente em 1851. O Imperial Observatório esteve ligado inicialmente às escolas militares, mas se tornou autônomo a partir de 1871, e organizou diversas missões científicas de determinação de coordenadas e observações planetárias e solares.

Os estudos geológicos começaram com a chegada de engenheiros alemães vindos com a Corte de D. João VI, como o Barão de Eschwege. Uma tentativa de estudar as 
riquezas minerais brasileiras, em boa parte frustrada por falta de conclusão do relatório final, foi a Comissão Científica de Exploração, que se deslocou ao Ceará em 1859.

A vinda ao Brasil de bons geólogos americanos nas décadas de 60 e 70, como Charles Hartt e Orville Derby, foi proveitosa para dar impulso às pesquisas nesse campo, inclusive através da Comissão Geológica do Império (1875-77). No entanto, esse trabalho não foi consolidado na criação de escolas de pesquisadores que pudessem desenvolver os métodos trazidos de fora (Stepan 1976: 47), em parte devido a limitações pessoais dos protagonistas, mas também devido à falta de interesse das elites e, conseqüentemente, do governo brasileiro na institucionalização da ciência. Talvez as províncias (depois estados) estivessem até mais motivadas para o assunto, como aconteceu com São Paulo que, já na República, faria um importante levantamento geográfico e geológico de suas terras, a partir da sua Comissão Geográfica e Geológica, criada em 1886.

O Brasil continuou no século XIX a buscar ouro e diamantes que haviam feito fortunas na época colonial e este foi o principal incentivo para a pesquisa mineral (Guimarães 1981: 89-103). Na esteira dessas buscas é que foram descobertos no início do século outros depósitos de minérios, como o salitre no Ceará, o carvão no sul do Brasil e a galena na Bahia. Ao longo do período monárquico sucedem-se a descoberta e exploração rudimentar de diversos outras jazidas, como as de minérios de cobre, chumbo e estanho. Detalhe curioso é a identificação da monazita em areias litorâneas da Bahia na década de 1880, que durante algum tempo foi contrabandeada ao exterior para a fabricação de camisinhas incandescentes para lampiões de gás, aproveitando o tório da areia monazítica.

Em geral a exploração das diversas jazidas foi de baixa eficiência, apesar do acúmulo crescente de conhecimentos técnicos de mineralogia e engenharia, provavelmente por falta de uma política nacional que orientasse os mineradores, que por sua vez esperavam fazer fortunas rapidamente.

Entrementes, houve esforços para criar a siderurgia brasileira em bases mais científicas. A produção de ferro em Minas Gerais foi iniciada pelo Intendente Câmara, que em 1814 já produzia ferro com um alto forno em Pilar do Carmo, perto de 
Diamantina. A partir do trabalho de arregimentação de profissionais alemães do ramo (como Eschwege e Varnhagen), empreendido por José Bonifácio de Andrada e iniciado em Portugal quando lá morava, na mesma década foi intensificada a produção da fábrica de Ipanema, em Sorocaba (Gomes 1983, cap. III).

A produção siderúrgica era porém muito pequena; em 1844 o Brasil dispunha de dois alto-fornos em Ipanema e, com as demais forjas menores, resultavam cerca de 1200 toneladas por ano - à guisa de comparação, nos EUA em 1810 já havia 110 altos-fornos, produzindo 54.000 toneladas por ano (Carrara/Meirelles 1996, I: 236). As fábricas mineiras fecharam sem incentivos para concorrer com os produtos de fora e a política de abertura a produtos importados adotada a partir de 1874 por Rio Branco fez regredir Ipanema e outras pequenas empresas siderúrgicas, que empregavam um de três processos: o dos cadinhos, o das forjas italianas e o das forjas catalãs.

Como mostra Francisco Magalhães Gomes, já em 1884 o primeiro aluno formado na Escola de Ouro Preto, Francisco de Paula Oliveira, escreve que a solução para a baixa atratividade e eficiência da siderurgia seria o governo provincial empreender uma fábrica e educar um corpo de operários nacionais (Gomes 1983: 105) - o que, como se sabe, só foi feito pelo governo Vargas muito mais tarde, durante a $2^{\mathrm{a}}$ Guerra Mundial.

Com a vinda da Corte portuguesa ao Brasil, ficou patente a dificuldade de continuar a importação de médicos (e engenheiros) da Europa. Os cursos práticos dados nos hospitais militares da Bahia e do Rio foram regularizados e em 1832 transformados em Escolas de Medicina, com currículo baseado na Faculdade de Medicina de Paris (Stepan 1976: 36). A farmacêutica brasileira foi artesanalmente desenvolvida nas boticas, em que pese o mérito de isto incentivar alguma indústria química, a partir dos primeiros laboratórios farmacêuticos. Um exemplo disto é a pioneira obtenção de alcalóides no Brasil (Valle 1978: 51), com a extração da pereirina por Ezequiel Correa dos Santos (pai).

Fundamental para a transição cultural do colonialismo para a independência foi a criação no Rio de Janeiro da Real Academia Militar, cujo decreto é de 1810 - por influência do ministro Rodrigo de Sousa Coutinho, Conde de Linhares, e que reunia um círculo mais progressista de intelectuais brasileiros e portugueses. Essa escola 
devia formar oficiais e técnicos para obras públicas, seguindo o modelo da Escola Politécnica de Paris, nessa época já difundido pela Europa. Na verdade, a instituição logo se defrontou com os problemas típicos do atraso brasileiro: falta de professores e instalações adequados, bem como de material didático (Figueiroa 1997: 61).

Em 1855 foi organizado o Batalhão de Engenheiros do Exército, que executou importantes trabalhos de fortificações militares, além da construção de linhas telegráficas e estradas. A separação das engenharias civil e militar começou em 1858, com a criação da Escola Central, apesar de ainda se subordinar ao Ministério da Guerra. Em 1876 foi fundada em Ouro Preto a pioneira Escola de Minas (que se dedicou também à metalurgia e posteriormente à engenharia civil e foi montada com professores franceses) e no Rio de Janeiro a Escola Politécnica (sucessora da Escola Central, mas agora completamente desmilitarizada). No entanto, como já assinalamos, não havia uma demanda significativa de engenheiros por parte de indústrias nacionais. As novas indústrias e as estradas de ferro continuavam a utilizar em larga medida técnicos e equipamentos estrangeiros. Houve algum aproveitamento dos formados em atividades de engenharia civil ou ainda no magistério e em cargos governamentais, mas muitos sequer exerceram sua profissão.

Até meados do século XVIII, a construção de navios era feita no Arsenal da Bahia, enquanto que o do Rio de Janeiro em geral executava reparos - a excelência até hoje dos saveiros baianos é um atestado remanescente da grande atividade de construção naval que houve em Salvador. Os projetos eram obra de construtores com formação puramente empírica, mais tarde contou-se com alguns engenheiros navais formados no estrangeiro. A modernização do Arsenal de Marinha da Corte se iniciou por volta de 1840, quando ali começaram a trabalhar engenheiros europeus; somente a partir de 1865 foi o estabelecimento dirigido por engenheiros brasileiros (Telles 1994: 296).

Em 1854 é lançado ao mar o primeiro navio brasileiro exclusivamente a vapor e com hélice, a corveta Ipiranga, projetada pelo engenheiro brasileiro Napoleão Level. A partir do período da Guerra do Paraguai (1865-70), o Arsenal do Rio de Janeiro se torna bastante importante, sendo bem equipado e produzindo não só 
navios, mas também armamentos, máquinas a vapor e outros equipamentos e peças. No auge de suas atividades, ali são inclusive feitas pesquisas tecnológicas, que geraram até patentes registradas no exterior, como o tipo de carena inventado pelo engenheiro Trajano de Carvalho em 1869 (Telles 1994: 308). Ao Arsenal se soma o estaleiro de Ponta d'Areia, do Visconde de Mauá, já referido anteriormente.

\section{Observações finais}

O final do Império coincide com a decadência do Arsenal de Marinha. Isto se deveu sem dúvida ao fato de o Arsenal ser um estabelecimento isolado, sem vínculo com estabelecimentos de ensino, pela inexistente institucionalização da pesquisa em metalurgia, materiais, etc. Como vimos, os dois grandes setores de produção de bens de capital no Brasil monárquico seriam as ferrovias e os estaleiros. Nossa siderurgia estava entretanto estagnada nesta época, ao passo que as ferrovias de capital inglês naturalmente traziam as locomotivas de fora; é nesse contexto que se verifica que a Marinha se dedicou isoladamente à produção local de bens de capital - um desentrosamento que ilustra significativa e claramente a falta de uma política industrial, ou melhor, a omissão governamental na definição de diretrizes de interesse nacional.

Caracteristicamente, as prioridades do Império foram no sentido de cimentar uma nação agro-exportadora, escravocrata e fortemente dependente da economia internacional. Somese a isto a carência das fontes de energia então usadas para a industrialização, como o carvão mineral, e a já mencionada deficiência dos meios de transporte e comunicação, que se tem elementos explicativos bastante fortes para entender o atraso da jovem nação.

Ao final do Império era flagrante a defasagem do Brasil com relação aos países desenvolvidos. Do ponto de vista cultural, havia ainda a dificuldade adicional para a industrialização, uma vez que a esta se opunham as elites adeptas do liberalismo econômico, pouco empreendedoras e que defendiam o consumo de bens importados, especialmente os manufaturados. Institucionalmente, não havia incentivo governamental para a industrialização, nem financiamento para tal. Tudo agravado porque tampouco havia mercado consumidor significativo, conseqüência entre outras causas da demora na abolição da escravatura. 
Não é demais insistir que o Império não logrou desenvolver o país devido à predominância na maior parte de suas elites dirigentes do pensamento liberal econômico, no sentido das doutrinas de Adam Smith. Estas foram veiculadas inicialmente por José da Silva Lisboa, Visconde de Cairu, mas elas persistiram e se desenvolveram em solo fértil - a elite escravagista e ligada à terra. Na história do Brasil, o Império vê suceder-se às elites coloniais do engenho e da mineração a dos barões do café, todas muito conservadoras. A ideologia liberal foi aqui adaptada com primor para sustentar os privilégios dessas elites, formadas por senhores de escravos, agro-exportadores e latifundiários.

Perdeu-se assim pelo menos uma boa oportunidade concreta de desenvolvimento, representada no tempo do Império pela acumulação de capital provinda da agricultura do café, com o concomitante crescimento das forças produtivas, visível na instalação das estradas de ferro e da navegação a vapor, bem como nalguma industrialização, conquanto acanhada.

Já se disse do Império que foi uma instituição liberal conservadora, que às vezes se transformava em conservadora liberal, ou seja, fazia tipicamente como o "leopardo" de Lampedusa: era preciso mudar para afinal tudo continuar na mesma - tradição de oportunismo que, a bem da verdade, no Brasil não tem sido prerrogativa apenas do Império.

\section{Referências Bibliográficas}

ALENCASTRO, Luiz Felipe de (org.). História da Vida Privada no Brasil, vol. 2 (Império: a Corte e a Modernidade Nacional). São Paulo: Companhia das Letras, 1997.

ANDRADA E SILVA, José Bonifácio de. Projetos para o Brasil (org. Míriam Dohlnikoff). São Paulo: Companhia das Letras, 1998.

BARRETO, Tobias. Introdução ao Estudo do Direito. São Paulo: Landy, 2001

CALDEIRA, Jorge. Mauá, Empresário do Império. São Paulo: Companhia das Letras, 1995.

CARRARA JR., Ernesto/ MEIRELLES, Hélio. A Indústria Química e o Desenvolvimento do Brasil - 1500-1889, tomos I e II. São Paulo: Metalivros, 1996.

CARVAlHO, José Murilo de. A Construção da Ordem - A Elite Política Imperial. Rio de Janeiro: Campus, 1980. 
COSTA, Cacilda Teixeira da. O Sonho e a Técnica - A Arquitetura de Ferro no Brasil. São Paulo: EDUSP, 1994.

DOMINGUES, Heloísa Maria Bertol. "A Sociedade Auxiliadora da Indústria Nacional e as Ciências Naturais no Brasil Império". (Notas técnico-científicas 002/96). Rio de Janeiro: Museu de Astronomia, 1996. (re-publicado em DANTES, Maria Amélia, Espaços da Ciência no Brasil, Rio de Janeiro: Fiocruz, 2001)

EISENBERG, Peter. Modernização sem Mudança - A Indústria Açucareira em Pernambuco, 1840/ 1910 (trad. João Maia). Rio de Janeiro/Campinas: Paz e Terra/ UNICAMP, 1977.

FIGUEIROA, Sílvia. As Ciências Geológicas no Brasil: Uma História Social e Institucional, 1875-1934. São Paulo: Hucitec, 1997.

GOMES, Francisco Magalhães. História da Siderurgia no Brasil. Belo Horizonte/São Paulo: Itatiaia/EDUSP, 1983.

GUIMARÃES, José Epitácio Passos. Epitome de História da Mineração. São Paulo: Art/ Secretaria de Estado da Cultura, 1981.

HAMBURGER, Amélia/ DANTES, Maria Amélia/ PATY, Michel/PETITJEAN, Patrick (orgs.). A Ciência nas Relações Brasil-França (1850-1950). São Paulo: EDUSP/FAPESP, 1996.

HAMILTON, Alexander. Relatório sobre as Manufaturas (trad. Geraldo Lino/Vitor Grünewaldt). Rio de Janeiro: Solidariedade Ibero-Americana, 1995.

LEMOS, Carlos A.C. Alvenaria Burguesa, $2^{a}$ ed. São Paulo: Nobel, 1989.

LIMA, Heitor Ferreira. História Político-Econômica e Industrial do Brasil (Brasiliana, vol. 347), $2^{a}$ ed. São Paulo: Cia. Editora Nacional, 1976.

LOPES, Maria Margaret. O Brasil Descobre a Pesquisa Científica: Os Museus e as Ciências Naturais no Século XIX. São Paulo: Hucitec, 1997

LUZ, Nícia Vilela. A Luta pela Industrialização do Brasil, 2ªed. São Paulo: Alfa-Ômega, 1975.

MENDES JR., Antônio/ RONCARI, Luiz/ MARANHÃO, Ricardo. Brasil História, vol.2 (Império). São Paulo: Brasiliense, 1977.

MOTOYAMA, Shozo (org.). Tecnologia e Industrialização no Brasil: Uma Perspectiva Histórica. São Paulo: UNESP, 1994.

PESAVENTO, Sandra Jutahy. Exposições Universais - Espetáculos da Modernidade do Século XIX. São Paulo: Hucitec, 1997.

POMPÉIA, Raul et alii. Um Monarca da Fuzarca (org. de Sérgio Goes de Paula). Rio de Janeiro: Relume-Dumará, 1993. 
PRADO JR., Caio. História Econômica do Brasil, 17ª ed. São Paulo: Brasiliense, 1974.

RAEDERS, Georges. O Inimigo Cordial do Brasil - O Conde de Gobineau no Brasil (trad. Rosa F. d'Aguiar). Rio de Janeiro: Paz e Terra, 1988.

STEPAN, Nancy. Gênese e Evolução da Ciência Brasileira - Oswaldo Cruz e a Política de Investigação Científica e Médica. Rio de Janeiro, 1976.

TELLES, Pedro Carlos da Silva. História da Engenharia no Brasil (Séculos XVI a XIX), $2^{\mathrm{a}}$ ed. Rio de Janeiro: Clube de Engenharia, 1994

VALLE, José Ribeiro do. A Farmacologia no Brasil - Antecedentes e Perspectivas. São Paulo: Academia de Ciências do Estado, 1978.

VARGAS, Milton (org.). História da Técnica e da Tecnologia no Brasil. São Paulo: UNESP, 1994. 